\title{
Gender differences in social cognitive determinants of exercise adoption
}

\author{
Nelli Hankonen ${ }^{a *}$, Pilvikki Absetz ${ }^{\mathrm{a}}$, Paolo Ghisletta ${ }^{\mathrm{b}}$, Britta Renner ${ }^{\mathrm{c}}$ \\ and Antti Uutela ${ }^{\mathrm{a}}$ \\ "Welfare and Health Promotion, National Institute for Health and Welfare, Mannerheimintie \\ 166, Helsinki, 00300 Finland; ${ }^{b}$ Faculty of Psychology and Educational Sciences, \\ University of Geneva, Methodology and Data Analysis Unit, Geneva, Switzerland; \\ 'Department of Psychology, University of Konstanz, Konstanz, Germany
}

(Received 27 May 2008; final version received 8 January 2009)

\begin{abstract}
Gender differences in lifestyle-related mortality and morbidity suggest a need to investigate gender-specificity of health behaviour change process and factors influencing it. We tested whether changes in self-efficacy beliefs and planning, as well as the level of social support predict change in exercise. Finnish men and women, aged 50-65 years, at an increased risk for type 2 diabetes were recruited from health care centres to participate in the Good Ageing in Lahti Region (GOAL) Lifestyle Implementation Trial. Psychosocial factors were measured with questionnaires and exercise with 7-day physical activity diaries at baseline and at 3 months. At baseline, no gender differences were found in self-efficacy and planning, but men reported receiving more social support than women. At 3 months, women reported having formed more action plans for changing their exercise routines than men. Among women, increase in selfefficacy and planning predicted increase in exercise. Among men, changes in planning played a less significant role. The more salient role of planning for women than for men, and the fact that women receive less social support, may reflect life circumstances allowing less spontaneous lifestyle decisions and a lower acceptance of lifestyle changes by their social environment.
\end{abstract}

Keywords: gender differences; physical activity; self-efficacy; planning; behaviour change; social support

\section{Introduction}

Unhealthy lifestyle, i.e. lack of physical activity (PA) and unhealthy eating, plays a central role in the development of major chronic diseases such as type 2 diabetes. Interventions targeting unhealthy lifestyles have been shown to reduce the risk of chronic diseases (Knowler et al., 2002; Tuomilehto et al., 2001). There are differences in lifestyle between men and women, which is also reflected in the differences in lifestyle-related morbidity and mortality (Arber, 2001). However, less is known about the psychosocial mechanisms and determinants of lifestyle change, and the role of gender therein is still underresearched. Accordingly, this study aims to specify whether a successful change in exercise is achieved through similar psychosocial processes among men and women.

\footnotetext{
*Corresponding author. Email: nelli.hankonen@thl.fi
} 
Health behaviour change among women and men

Obesity, abdominal obesity and abnormal glucose metabolism are common among Finnish middle-aged and older adults and a significant part of the population should change their lifestyle in order to prevent type 2 diabetes and its complications (Peltonen et al., 2006). An important aspect of a healthy lifestyle is regular PA, which is beneficial, e.g. for weight loss and cardiovascular risk factors (Shaw, Gennat, O'Rourke, \& Del Mar, 2006).

Women in almost all countries were expected to outlive men by the year 2006 (Barford, Dorling, Smith, \& Shaw, 2006), which can, for a large part, be explained by women's healthier lifestyle. However, for those women who lead an unhealthy lifestyle, changing it into a healthier one after participating in a lifestyle change programme or intervention seems to be at least as hard (e.g. Assaf et al., 2003) or even harder than for men (e.g. Rejeski et al., 2003). In intervention studies, merely reporting behavioural outcomes by gender is not enough, we need to know what produces the existing gender differences in lifestyle or in lifestyle change. Thus, what we need is a more in-depth analysis (Exploring Concepts of Gender and Health, 2003) that would reveal whether there are gender differences also in the psychological processes behind successful lifestyle change.

\section{The role of psychosocial factors in health behaviour change}

Central factors facilitating adoption of new behaviours are a person's confidence in being capable of making the necessary changes and her/his actual skills in controlling or regulating behaviour (Bandura, 1997; Gollwitzer \& Sheeran, 2006; Sniehotta, Schwarzer, Scholz, \& Schüz, 2005b). The two most important constructs representing these are self-efficacy and planning, which seem to be the best predictors of many health behaviours amongst a broad range of psychosocial variables identified by past research (Schwarzer et al., 2007).

Self-efficacy beliefs concern the individual's beliefs about her or his capabilities to execute a sequence of actions (Bandura, 1986, 1997). Action self-efficacy is relevant in adopting a new behaviour, and it consists of optimistic beliefs about one's capability to initiate the novel behaviour (Schwarzer \& Renner, 2000). High-efficacious individuals tend to approach more challenging tasks, put forth more effort to execute them and be more persistent when facing aversive stimuli (Bandura, 1986).

Action planning refers to the process of specifying when, where and how to act according to one's intentions, and action plans increase the likelihood of carrying out the intended behaviour (Leventhal, Singer, \& Jones, 1965; Sniehotta et al., 2005b), such as PA and exercise behaviours (Lippke, Ziegelmann, \& Schwarzer, 2004; Renner, Spivak, Kwon, \& Schwarzer, 2007; Sniehotta, Scholz, \& Schwarzer, 2005a; Sniehotta et al., $2005 b$ ). Action planning triggers the initiation of action without additional investment in self-regulatory effort.

The social environment may either facilitate or hinder health behaviour change (Lewis \& Rook, 1999; Schwarzer \& Fuchs, 1996). Thus, for instance, positive social support from friends or family members may enhance both initial weight loss and maintenance of the lowered weight (Wing \& Jeffery, 1999). Even if social support is often not directly targeted by lifestyle interventions, social support provided by the participants' family and friends (or the lack of it) may play an indirect role in the lifestyle change process. One of the routes through which social support may influence 
lifestyle change is self-efficacy: those who receive more support are also more likely to increase their self-efficacy beliefs (Bandura, 1997; Schwarzer \& Knoll, 2007), and enhanced self-efficacy works to enable behaviour change (Bandura, 1997).

It is often implicitly assumed that social cognitive models are universal. However, for example, the Health Action Process Approach (HAPA) has been found to model health behaviour of middle-aged and older persons better than that of younger persons (Renner et al., 2007). However, not many empirical research attempts have been made to establish whether the same processes apply across genders or whether there are gender-specific processes in health behaviour interventions, despite the recommendations of reporting both process and outcome data for gender subgroups (Whitlock \& Williams, 2003).

Although some meta-analyses find that men and women are psychologically more similar than different (Hyde, 2005), there is some empirical evidence about gender differences in the domain of self-regulation. Planning was associated with healthier dietary behaviours among South Korean women but not among men (Renner et al., 2008). According to a meta-analysis, women, on average, can better delay gratification than men (Silverman, 2003). School girls have also been found to use planning and self-regulation more than boys of same age (Martin, 2004; Tangney, Baumeister, \& Boone, 2004), implying that gender-specific behavioural strategies are adopted early in gender role socialisation. The above findings suggest that women and men may not benefit in a similar manner from behaviour modification techniques involving self-regulation with explicit planning.

Until now, social cognitive health behaviour models have been mainly used for explaining behaviour, not behaviour change. For this purpose, cross-sectional study designs have been sufficient. Intervention studies provide an ideal setting to study change. There is, however, a lack of dynamic health behaviour change models tracking change processes in longitudinal empirical research.

The counselling sessions of the present intervention study, GOAL Lifestyle Implementation Trial (Uutela et al., 2004), were planned based on the HAPA (Schwarzer \& Fuchs, 1996) to target the critical components of health behaviour change. The goal of the group counselling was to facilitate a lifestyle change that would lead to specific PA and nutrition objectives previously shown to reduce the risk for diabetes (Tuomilehto et al., 2001). In the GOAL lifestyle implementation trial, men showed better improvement in clinical risk factors than did women (Absetz et al., 2007), suggesting that also the lifestyle change process might differ between the genders.

\begin{abstract}
Aims of the study
This study has two aims: The first is to examine whether men and women experience the same kinds of psychosocial processes related to self-efficacy, planning and social support during a lifestyle change intervention. The second aim is to study whether the psychosocial processes play a different role in predicting behaviour change, i.e. exercise adoption, for the two genders.
\end{abstract}

\title{
Method
}

Study setting

The study is a sub-study of the Lifestyle Implementation Trial to prevent type 2 diabetes, an intervention conducted within the GOAL research and development program 
(Good Ageing in Lahti Region, Ikihyvä Päijät-Häme). Middle-aged persons (50-65 years) with at least moderate risk for type 2 diabetes were recruited into lifestyle counselling groups facilitated by trained nurses. The intervention programme and its components have been described in detail in Uutela et al. (2004) and the setting and implementation in Absetz et al. (2007).

The ethical commission in Päijät-Häme hospital district reviewed the study protocol of the Lifestyle implementation trial and gave its approval to the project. All data are kept and handled according to the instructions and requirements of good scientific procedures by the Finnish National Public Health Institute (currently National Institute for Health and Welfare). Informed consent was received from the participants, and they were treated according to the American Psychological Association (APA) ethical guidelines.

\section{Sample}

The study employs a prospective longitudinal design. The psychosocial factors and behaviour were measured with mailed questionnaires before the intervention at baseline (T1) and after the main part of the intervention, 3 months after the baseline (T2). Altogether 385 participants (men, $N=103,26.8 \%$; women, $N=282,73.2 \%$ ), aged $50-65$ participated in the programme. From the original data set, including 393 participants, 4 participants without any needed data, and 4 participants with only risk factor data at baseline were excluded from these analyses. Pre-intervention, $95.5 \%$ of the participants were classified as overweight (BMI $>25)$ or obese $(\mathrm{BMI}>30)$. The average BMI was similar for both genders (men: $M=32.4, \mathrm{SD}=5.2$, women: $M=32.7, \mathrm{SD}=5.0$ ). At baseline, women's average weekly exercise minutes $(M=81.4, \mathrm{SD}=111.81)$ were significantly higher that those of $\operatorname{men}(M=39.0, \mathrm{SD}=78.6)(F(1,319)=10.86, p<0.001)$.

The response rate to the first questionnaire was $100 \%$ for men and $99.3 \%$ for women. The attendance rate at the 3-month follow-up for men $(96.1 \%)$ and women $(94.3 \%)$ was equally high. Additional analyses comparing completers and drop-outs yielded no significant differences with respect to self-efficacy, social support, BMI and education. A similar picture emerged when testing within men and women. No significant differences between men who continued to participate and men who did not continue emerged. Within women no significant differences were found expect for one. The 16 female dropouts reported at baseline significantly $(p=0.026)$ less action planning than did the 259 women who stayed in the programme $(M=2.13$ versus $M=2.57)$. Since the variable related to the missingness mechanism is included in the model, the full information maximum likelihood (FIML) estimation used allows unbiased parameters estimates for all parameters of the model (Graham, 2003).

\section{Measures}

Self-efficacy concerning PA was measured with five items (Schwarzer \& Renner, 2000) (e.g. 'I can manage to carry out my exercise intentions, even if I need a long time to develop the necessary routines/even if $I$ have to make a detailed plan regarding exercise') (Cronbach's $\alpha=0.92$ at baseline). Possible responses ranged from 'very certain I cannot' (1) to 'very certain I can' (4). Planning for exercise was measured with four items (Sniehotta et al., 2005b) (e.g. 'I have made a detailed plan regarding when to exercise/where to exercise') (Cronbach's $\alpha=0.94$ at baseline). Possible responses ranged from 'definitely false' (1) to 'definitely true' (4). Social support provided by family, friends 
and relatives during the last 3 months was measured at baseline with an adapted and shortened version of a scale for participation in PA (Sallis, Grossman, Pinski, Patterson, \& Nader, 1987) (e.g. 'How often have those close to you (friends, family or relatives) ... changed their schedule so that you could exercise together/encouraged you to maintain your exercise habit/exercised with you') (Cronbach's $\alpha=0.85$ ). Possible responses were 'never' (1), 'sometimes' (2), and 'often' (3)'. The brief 5 -item version and the original 11 -item version scale correlated with $r=0.96$. Thus, only highly redundant items were excluded in order to generate a more parsimonious measure facilitating a better sample size to parameter ratio for the structural equation modelling (SEM).

Physical activity was measured as average minutes per day, monitored over a 1-week period, with every 10 minutes of activity recorded in a diary at $T 1$ and at $T 2$. Participants reported their PA divided into two types of light-intensity PA and three categories of moderate-to-vigorous-intensity PA, including, e.g. gymnastics, ball games and jogging. For the statistical analyses, the weekly number of minutes of moderate-to-vigorousintensity PA was used. In the current study, we focus on moderate-to-vigorous-intensity PA because it tends to increase the magnitude of weight loss and result in greater reduction of fasting serum glucose than lower intensity exercise does (Shaw et al., 2006).

\section{Statistical analyses}

Structural equation modelling was used to examine the change processes. Statistical analyses were conducted with the Mplus version 5.1 software. Data that were missing were treated by FIML estimation.

In order to be sure that the factors are well defined, confirmatory longitudinal factor models were tested for the self-efficacy and planning constructs (McArdle \& Nesselroade, 1994). This model presupposes that the constructs are well represented by manifest variables, which were measured repeatedly over time. At each time point, the best factorial representation of each factor is specified and the factors are allowed to correlate over time. To assure that the factors' meaning does not change in time, factorial invariance was enforced, by constraining the same factor loadings for the constructs at time 1 (T1) and time 2 (T2) (Horn \& McArdle, 1992). To test measurement invariance across gender groups, we further constrained the loadings to be equal across women and men. The constrained models can then be compared to more relaxed models, which do not enforce equality of parameters. If the loss in statistical fit due to the constraints is not significant, we retain the constrained (but also more parsimonious) models.

Structural equation modelling not only allows defining the structure of the measured variables in terms of variances and covariances; but also in terms of means and intercepts. The aim of the first question is to assess whether men and women have similar or different levels of self-efficacy and planning, both at $T 1$ and $T 2$. To address this, we compared models forcing the same factor means across women and men with models that allowed gender specific factor means.

To address the second question, which centers explicitly on change, we applied a variation of the previous model called Latent Difference Score Model (McArdle \& Nesselroade, 1994). This model builds upon the previous factorial representations, but forces a particular relation between the $T 1$ and $T 2$ factors. This relation defines a difference factor, which represents the change in the factorial score for each individual between $T 2$ and $T 1$. The model, then, explicitly specifies the starting point (T1, before intervention) and the change (between $T 2$ and $T 1$ ), so that both facets can be clearly 


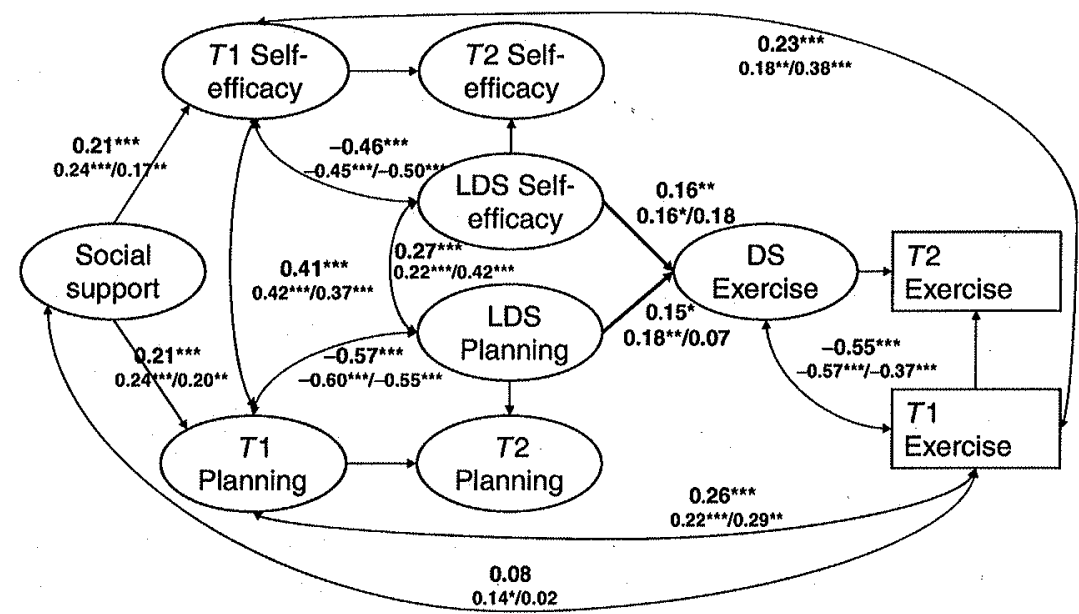

Figure 1. Psychological determinants of changes in exercise behaviour. Three estimates for each parameters are shown: first the overall estimate (Model A), followed by the estimates for women/ men (Model B). Standardised coefficients. The indicators of the latent variables and some of the covariances are excluded for presentation purposes. All of the covariances were allowed to be estimated in the model. ${ }^{* * *} p<0.001,{ }^{* *} p<0.01,{ }^{*} p<0.05$.

examined. This approach avoids measurement problems common to difference scores calculated at the manifest level, because change is entirely defined in latent space, hence free of unreliability issues. We applied this model to both self-efficacy and planning as a multivariate latent difference score model (MLDSM) specification. Again, we enforced loading invariance across time and across gender for both factors, to be sure that the factors' meaning is the same across both time points and genders. This model is represented in Figure 1, where for simplicity only the essential components are portrayed (i.e. the social support, self-efficacy and planning indicators are excluded).

In Figure 1, ovals represent latent variables, squares represent manifest variables (only included for exercise), one-headed arrows represent regression paths, two-headed arrows represent correlations and, as conventional, unlabelled paths represent regression weights of size 1 (Boker, McArdle, \& Neale, 2002). In Figure 1, the two ovals named LDS mark the change between $T 1$ and $T 2$ in self-efficacy and planning. For exercise the change is not estimated at the latent level, because there was only one marker. We were particularly interested in the effects of self-efficacy and planning on exercise. To test the equality of these regression paths, we tested a model constraining the regression paths to be equal across gender against a model without these restrictions.

To assess the models' overall statistical adjustments to the data we use the Chi square $\left(\chi^{2}\right)$ statistic (with its degrees of freedom), the comparative fit index (CFI), the Tucker-Lewis index (TLI) and the root-mean-square-error of approximation (RMSEA). Because the $\chi^{2}$ test statistic is sample size dependent, we used the normal cutoff recommendations for the rest of the indices (Hair, Black, Babin, Anderson, \& Tatham, 2006). For example, a model with more than 30 observed variables and with sample size over 250 has a good fit, if the values of CFI and the TLI are above 0.90 , and the values of the RMSEA less than 0.07 (with CFI of at least 0.90 ). To compare statistically nested models (i.e. those with and without equality constraints on parameters of interest) we used the difference in the $\chi^{2}$ values of the two models distributed as the difference in their degrees of freedom. A significant difference in $\chi^{2}$ values leads to retain the less 
parsimonious models, without the equality constraints, whereas a non-significant difference in fit provides evidence for the tenability of the equality constraints.

\section{Results}

\section{Measurement models}

To test measurement invariance across both measurement times and gender groups for self-efficacy and planning, five confirmatory longitudinal factor models were tested (Table 1). These models test whether the loadings of self-efficacy and planning are the same at $T 1$ and $T 2$ as well as across men and women. All models obtained satisfactory adjustments.

In Table 1, we show the $\chi^{2}$ difference test results and whether there were significant differences in fit between the models. First, models (M1 and M3) with freely estimated T1- and T2-loadings were specified for both gender groups separately. Then, the same $T 1$ - and $T 2$-loadings for self-efficacy were enforced (M2 and M4) in each group separately. Finally, the same T1- and T2-loadings were enforced on both men and women (M5). First, for women we obtained factorial invariance across time (M1 and M2 differ in 2.305 $\chi^{2}$ points for $\mathrm{df}=7$, which is a non-significant difference, $p=0.941$ ). In men we obtained similar results (M3 and M4 differ in $11.269 \chi^{2}$ points for $\mathrm{df}=7, p=0.127$ ). These two results allow us to compare the two gender-specific models with $T 1$ and T2-factorial invariance (M2 and M4) to the overall model that is invariant not only across time but also across gender (M5). This comparison yields a non-significant difference in $\chi^{2}$ value of 9.19 for $7 \mathrm{df}(p=0.239)$. Thus, we can conclude that the constructs are invariably measured (i.e. have the same meaning) at $T 1$ and $T 2$ and across both gender groups.

To test measurement invariance across groups for social support, two confirmatory factor analyses were tested (Table 2), all with satisfactory adjustments to the data. The first model (M6) estimated different factor loadings for men and women, whereas the second model (M7) enforced factorial invariance across the gender groups. The loss in fit was non-significant (difference in $\chi^{2}$ of 1.5 for $5 \mathrm{df}, p=0.913$ ). Measurement invariance across genders could hence be concluded. Again, this means that the factor has the same meaning for both women and men.

To summarise, the measurement and the structure of all three constructs are the same for women and for men. This allows us to apply the MLDSM to the three constructs to compare the factors and study their change.

\section{Mean comparisons}

The first study goal was to investigate whether men and women differ in terms of the psychosocial factors, i.e. the equalities of factor means. For each factor, a model that constrained the means to be similar across both genders was specified, and each model was compared to one that allowed the means to be different. Means of three factors were similar for men and women, but two were different. First, the model constraining the planning means at $T 2$ to be similar obtained a significantly $(p<0.05)$ worse fit $\left.\left(\chi^{2}(290)=576.10\right) ; \Delta d f=1, \Delta \chi^{2}=5.18\right)$, indicating that women increased their planning more during the intervention. Second, a model (M8 in Table 2) constraining the means of social support to be equal across both genders was significantly worse (difference in $\chi^{2}$ of 7.07 for $\left.1 \mathrm{df}, p=0.007\right)$ than one allowing them to vary between the genders. 
Table 1. Longitudinal measurement models for self-efficacy and planning.

\begin{tabular}{|c|c|c|c|c|c|c|c|}
\hline & $\Delta \chi^{2}(\mathrm{df} ; p)$ & $x^{2}$ & df & $p$ & CFI & TLI & RMSEA \\
\hline M1: Different $T 1-T 2$ loadings for women & & $(N=282) 351.505$ & 134 & $<0.0001$ & 0.949 & 0.942 & $0.076(0.066,0.086)$ \\
\hline M2: Same $T 1-T 2$ loadings for women & $2.305(7 ; \mathrm{ns})$ & $(N=282) 353.810$ & 141 & $<0.0001$ & 0.950 & 0.946 & $0.073(0.064,0.083)$ \\
\hline M3: Different $T 1-T 2$ loadings for men & & $(N=103) 196.569$ & 134 & 0.0004 & 0.957 & 0.951 & $0.067(0.046,0.087)$ \\
\hline M4: Same $T 1-T 2$ loadings for men & $11.269(7 ; \mathrm{ns})$ & $(N=103) 207.928$ & 141 & 0.0002 & 0.954 & 0.950 & $0.068(0.047,0.087)$ \\
\hline $\begin{array}{l}\text { M5: Same } T 1-T 2 \text { loadings for both } \\
\text { groups together }\end{array}$ & $\begin{array}{l}\text { Compared to } \\
\text { M2+M4) } 9.19(7 ; \mathrm{ns})\end{array}$ & $(N=385) 570.925$ & 289 & $<0.0001$ & 0.951 & 0.948 & $0.071(0.063,0.080)$ \\
\hline
\end{tabular}

Note: $\mathrm{df}=$ degrees of freedom, $\mathrm{CFI}=$ Comparative fit index, $\mathrm{TLI}=$ Tucker-Lewis index, RMSEA = Root-mean-square-error of approximation. 
Table 2. Measurement model for social support $(T 1)$.

\begin{tabular}{lccccccc}
\hline & $\Delta \chi^{2}(\mathrm{df} ; p)$ & $\chi^{2}$ & df & $p$ & CFI & TLI & RMSEA \\
\hline $\begin{array}{l}\text { M6: Different loadings } \\
\text { for women and men }\end{array}$ & 41.27 & 17 & 0.0009 & 0.966 & 0.960 & $0.087(0.053,0.121)$ \\
$\begin{array}{c}\text { M7: Same loadings for } \\
\quad 1.5(5 ; \mathrm{ns})\end{array}$ & 42.77 & 22 & 0.0050 & 0.971 & 0.973 & $0.070(0.038,0.102)$ \\
$\begin{array}{c}\text { Momen and men } \\
\text { क: Same mean for } \\
\text { women and men }\end{array}$ & $7.07(1 ; p<0.01)$ & 49.84 & 23 & 0.0010 & 0.962 & 0.967 & $0.078(0.048,0.108)$ \\
\hline
\end{tabular}

Note: $\mathrm{df}=$ degrees of freedom, $\mathrm{CFI}=$ Comparative fit index, TLI $=$ Tucker-Lewis index, RMSEA = Root-mean-square-error of approximation.

Table 3. Estimates of factor means (and standard deviations) of self-efficacy and planning (women's estimates from M2 and men's estimates from M4) and social support (multiple-group model M7).

\begin{tabular}{lccccc}
\hline & Self-efficacy $T 1$ & Self-efficacy $T 2$ & Planning $T 1$ & Planning $T 2$ & Social support $T 1$ \\
\hline Women & $3.1(0.48)$ & $3.2(0.52)$ & $2.6(0.79)$ & $3.0(0.71)$ & $2.0(0.56)$ \\
Men & $3.1(0.51)$ & $3.1(0.50)$ & $2.5(0.72)$ & $2.7(0.78)$ & $2.2(0.54)$ \\
& ns & ns & ns & $p<0.05$ & $p<0.05$ \\
\hline
\end{tabular}

Indeed, women received less support than men. See Table 3 for the estimates of factor means for men and women.

\section{Multivariate latent difference score models}

The MLDSM, with loading invariance across time and gender for self-efficacy and planning and invariance across gender for social support is displayed in Figure 1. This model defines (a) a latent difference score for self-efficacy and (b) one for planning for exercise, (c) the social support latent variable and (d) the baseline and difference scores for exercise. Figure 1 displays the parameter estimates for the whole sample together (Model A), and also the gender-specific parameter estimates from a multiple-group model (Model B). The model fit indices for Model A were as follows: $\chi^{2}(272)=591.72$ $(p<0.001), \mathrm{CFI}=0.95, \mathrm{TLI}=0.95, \mathrm{RMSEA}=0.055 ; 90 \%$ CI $[0.049-0.061]$. For Model $\mathrm{B}$ the indices were: $\chi^{2}(558)=923.56(p<0.001), \mathrm{CFI}=0.94, \mathrm{TLI}=0.94, \mathrm{RMSEA}=$ $0.058 ; 90 \% \mathrm{CI}[0.052-0.065]^{2}$

The second study goal was to investigate whether changes in self-efficacy and planning associate differently with exercise change in men than they do in women. The MLDSM enforcing equality of the regression paths (Model C) was tested against the model allowing gender-specific estimation of the parameters (Model B). The Model C yielded a good fit $\chi^{2}(562)=931.04(p<0.001), \mathrm{CFI}=0.94, \mathrm{TLI}=0.94, \mathrm{RMSEA}=0.058$; $90 \% \mathrm{CI}[0.052-0.065]$, and the $\chi^{2}$ difference test (difference in $\chi^{2}$ of 7.48 for $4 \mathrm{df}, p=0.11$ ) suggested that Model C was superior to Model B. Thus, even though there seems to be gender differences in the regression weights, the analyses did not confirm that the gender groups differ with significance level of $p<0.05$. 
A notable gender difference is found in the correlation between baseline exercise and exercise difference score (Women: $r=-0.56$, Men: $r=-0.37$ ). The correlation is significantly $(p<0.05)$ higher for women, that is, among women, lower baseline exercise levels predict steeper increases than among men.

\section{Discussion}

The first goal of the present study was to investigate whether men and women differ in terms of key psychosocial factors related to exercise during a lifestyle change intervention. Men in fact received more social support for PA than women. At 3 months, women had increased their exercise plans more than men. No other gender differences in the psychosocial determinants were found. The second goal was to establish whether changes in exercise are predicted by different psychosocial processes for men and women. Even though the correlation and regression weights were higher for women than for men, implying that planning was more important for women than for men, this pattern of results was not confirmed in the SEM analysis. However, this could be attributable at least partly to the sample size. Additionally, the gender difference in correlation between the baseline exercise and exercise difference score supports the finding that increases in planning seem to be more important for women than for men.

Changes in and effects of self-efficacy were similar across genders. This study confirmed that self-efficacy is a robust and reliable predictor of health behaviour and health behaviour change. The comparably weak regression coefficient found may depend on the fact that the independent and dependent variables are dynamic change variables, instead of stable variables representing levels at a specific measurement point. The results implicate that the larger the gain in self-efficacy during the intervention, the more increases in exercise follow.

Pre-intervention social support seems to play an important role for both genders in influencing self-efficacy and planning, underlining the importance of social environment in lifestyle change. Women received significantly less social support than men, consistent with other studies (e.g. Schwarzer \& Gutiérrez-Doña, 2005), which predisposes women for a less benign environment for lifestyle change attempt from the start.

The role of planning for exercise increase seems to be more vague: the data suggest that an increase in planning benefits women, but not men, although the result remains statistically ambiguous. This might be due to the smaller sample size of men, but also other methodological issues should be considered when interpreting the results. First, there might be gender-specific reporting biases: women may simply report their planning differentially. For example, women have been found to be more likely to report making attempts to change risk behaviours (Assaf et al., 2003). However, most similar studies are based on self-measurement of psychological constructs. Second, as women already in the baseline exercise more, they might have less room for change in the outcome variable. Nonetheless, the low baseline-levels point to a need for both genders to increase their activity to reach recommended levels. Third, the sample might be selective in that the lifestyle groups may contain especially motivated men compared to women. Culturally, women have been more concerned with weight loss and conscious of health issues in general (Lee, 1998). Women are more likely to participate in lifestyle change programmes than men (Assaf et al., 2003). It seems plausible to suppose that the fewer men participating are those with a better chance of success. 
Fourth, a gender difference in attendance rate of the intervention sessions might have caused the found differences. However, additional analyses showed no difference in the attendance rate in any sequence of the intervention session for men and women. Moreover, differential attendance rate in dependence of gender should have affected all study variables equally (e.g. self-efficacy).

The results regarding women's more extensive use and stronger effects of action planning are in line with earlier research findings. Women have been shown to use self-regulation more than men also in many other areas of life such as healthy diet (Renner et al., 2008) and academic performance (Tangney et al., 2004).

One might speculate that this type of self-regulation is socialised with the gender role. The social roles related to gender set practical demands, e.g. care-giving demands which could constrain women's exercise participation (Verhoef, Love, \& Rose, 1992). In general, women's opportunities to take time for themselves are narrower than men's: 50-64-year-old Finnish men typically spend less time on household chores than women. For example for food preparation, women use on average $61 \mathrm{~min}$ per day, men use only $24 \mathrm{~min}$ (Saastamoinen, 2005). Moreover, women's dual role in household and the workforce might pose a greater restriction for their leisure time and severe burden for their health (Hunt \& Annandale, 1993). Thus, women might need to plan more how to incorporate additional activities in their daily routine and they might even perceive a higher need to protect their health. In this context, taking the time for physical exercise might require more careful planning in the case of women compared to men. Hence, the overt psychological gender difference in the relevance of planning may reflect a more general, societal gender role structure. Moreover, it might be also a selfregulation technique that is more easily promoted among women in a lifestyle change intervention, as reflected by the greater increase in planning among women. However, this needs to be tested in further research including measures for the need of selfregulation and social barriers.

The results overall suggest that men and women do not differ generally in socialcognitive variables, but rather in those cognitions that are related to their social role as discussed for the case of planning. Moreover, the lower level of social support for women might point in the same direction: Women might receive less support from their spouses or family because spending time on non-family related activities might affect the daily routine in families more strongly than in the case of men. One practical implication for interventions would be to support women more in planning to change behaviour but also to facilitate their ability to activate social support sources.

The strengths of the study include the investigation of gender-specific psychosocial determinants and processes of health behaviour change, strong external validity provided by the context of a real-world health behaviour intervention, focus on dynamic behaviour change processes instead of static variables and the use of relevant methodology with sophisticated treatment of missing data, measurement error and modelling of change. Health behaviour theory and practice would likely benefit from a more explicit focus on dynamic changes in behaviour. As the present results suggest, changes might show differential patterns of associations compared to cross-sectional or static associations.

The study has also limitations. First, measures of social factors reflecting genderspecific life circumstances and opportunities were not included. Additional information regarding e.g. caretaking responsibilities in the family might add to our understanding of gender differences in exercise adoption over and above cognitive determinants, and should be addressed by future studies. Second, although important, planning is only one 
facet of a self-regulatory behaviour essential for regular exercise behaviour. Other facets such as self-monitoring of behaviour, feedback, evaluation and use of other control mechanisms (Maes \& Karoly, 2005) might also have gender-specific effects. Third, there are limitations regarding the sample size and possible self-selection of the sample. Although Finnish women and men have similar risk for diabetes, its prevalence is higher among men (Peltonen et al., 2006). Still, the majority of our intervention participants were women, reflecting the reality that women use medical services generally more often and are more concerned about their weight than men. The results can only be generalised to those men and women voluntarily attending a lifestyle change programme, they may not describe the behaviour change processes for people pursuing change on their own. Additionally, it must be borne in mind that gender differences found might not necessarily be fixed and unalterable, and it must be remembered that neither women nor men constitute a homogenous group but are diverse in, e.g. ethnicity and socioeconomic background.

In conclusion, the present study suggests that health cognitions change in different ways among men and women during a lifestyle intervention, and that the change in cognitions predicts behaviour change differentially. Compared to men, women's life circumstances on average might allow less spontaneous lifestyle decisions and their social environment provides less support for lifestyle change. Future research regarding theories and models of health behaviour change should further explore the idea that the driving forces for behaviour change may not be universal but rather dependent on gender roles or other significant factors such as life course, socioeconomic background or culture.

\section{Notes}

1. Only 3.5-5\% had chosen 'does not apply'. In the analyses, the response alternative 'does not apply' was coded as 'never'. Control analyses with 'does not apply' coded as missing yielded identical results.

2. In Models B and C, to apply the most parsimonious model, the means of self-efficacy at $T 1$, self-efficacy difference score, and planning at $\mathrm{T} 1$ were constrained to be equal across the genders.

\section{References}

Absetz, P., Valve, R., Oldenburg, B., Heinonen, H., Nissinen, A., Fogelholm, M., et al. (2007). Type 2 diabetes prevention in the 'Real World': One-year results of the GOAL implementation trial. Diabetes Care, 30(10), 2465-2470.

Arber, S. (2001). Gender and physical health. In N.J. Smelser, \& P.B. Baltes (Eds.), International encyclopedia of the social \& behavioral sciences (pp. 5960-5965). Oxford: Pergamon.

Assaf, A.R., Parker, D., Lapane, K.L., Coccio, E., Evangelou, E., \& Carleton, R.A. (2003), Does the $\mathrm{Y}$ chromosome make a difference? Gender differences in attempts to change cardiovascular disease risk factors. Journal of Women's Health, 12(4), 321.

Bandura, A. (1986). Social foundations of thought and action: A social cognitive theory. Upper Saddle River, NJ: Prentice-Hall.

Bandura, A. (1997). Self-efficacy: The exercise of control. New York: Freeman \& Co.

Barford, A., Dorling, D., Smith, G.D., \& Shaw, M. (2006). Life expectancy: Women now on top everywhere. British Medical Journal, 332(7545), 808.

Boker, S.M., McArdle, J.J., \& Neale, M. (2002) An algorithm for the hierarchical organization of path diagrams and calculation of components of expected covariance. Structural Equation Modeling, 9, 174-194. 
Exploring Concepts of Gender and Health (2003). Retrieved March 21, 2006, from http://www.hcsc-gc.ca/english/women/exploringconcepts.htm

Gollwitzer, P.M., \& Sheeran, P. (2006). Implementation intentions and goal achievement: A meta-analysis of effects and processes. Advances in Experimental Social Psychology, 38, 69-119.

Graham, J.W. (2003). Adding missing-data-relevant variables to FIML-based structural equation models. Structural Equation Modeling, 10, 80-100.

Hair, J.F., Black, W.C., Babin, B.J., Anderson, R.E., \& Tatham, R.L. (2006). Multivariate data analysis (6th ed.). Upper Saddle River, NJ: Prentice Hall.

Horn, J.L., \& McArdle, J.J. (1992). A practical and theoretical guide to measurement invariance in aging research. Experimental Aging Research, 18, 117-144.

Hunt, K., \& Annandale, E. (1993). Just the job? Is the relationship between health and domestic and paid work gender-specific? Sociology of Health and Illness, 15(5), 632-664.

Hyde, J.S. (2005). The gender similarities hypothesis. American Psychologist, 60(6), 581-592.

Knowler, W.C., Barrett-Connor, E., Fowler, S.E., Hamman, R.F., Lachin, J.M., Walker, E.A., et al. (2002). Reduction in the incidence of type 2 diabetes with lifestyle intervention or metformin. New England Journal of Medicine, 346(6), 393-403.

Lee, C. (1998). Women's health: Psychological and social perspectives. Thousand Oaks: Sage.

Leventhal, H., Singer, R., \& Jones, S. (1965). Effects of fear and specificity of recommendation upon attitudes and behavior. Journal of Personality and Social Psychology, 2(1), 20-29.

Lewis, M.A., \& Rook, K.S. (1999). Social control in personal relationships: Impact on health behaviors and psychological distress. Health Psychology, 18(1), 63-71.

Lippke, S., Ziegelmann, J.P., \& Schwarzer, R. (2004). Behavioral intentions and action plans promote physical exercise: A longitudinal study with orthopedic rehabilitation patients. Journal of Sport \& Exercise Psychology, 26(3), 470 483.

Maes, S., \& Karoly, P. (2005). Self-regulation assessment and intervention in physical health and illness: A review, Applied Psychology: An International Review, 54(2), 267-299.

Martin, A. (2004). School motivation of boys and girls: Differences of degree, differences of kind, or both? Australian Journal of Psychology, 56(3), 133-146.

McArdle, J.J., \& Nesselroade, J.R. (1994). Using multivariate data to structure developmental change. In S.H. Cohen, \& H.W. Reese (Eds.), Life-span developmental psychology: Methodological contributions (pp. 223-267). Hillsdale, NJ: Lawrence Erlbaum Associates.

Peltonen, M., Korpi-Hyövälti, E., Oksa, H., Puolijoki, H., Saltevo, J., Vanhala, M., et al. (2006). Lihavuuden, diabeteksen ja muiden glukoosiaineenvaihdunnan häiriöiden esiintyvyys suomalaisessa aikuisväestössä - Dehkon 2D-hanke (Prevalence of obesity, type 2 diabetes, and other disturbances in glucose metabolism in Finland - The Fin-D2D survey). Suomen Lääkärilehti, 61(3), 163-170.

Rejeski, W.J., Brawley, L.R., Ambrosius, W.T., Brubaker, P.H., Focht, B.C., Foy, C.G., et al. (2003). Older adults with chronic disease: Benefits of group-mediated counseling in the promotion of physically active lifestyles. Health Psychology, 22(4), 414-423.

Renner, B., Kwon, S., Yang, B.-H., Paik, K.-C., Kim, S.H., Roh, S., et al. (2008). Social-cognitive predictors of dietary behaviors in South Korean men and women. International Journal of Behavioral Medicine, 15(1), 4-13.

Renner, B., Spivak, Y., Kwon, S., \& Schwarzer, R. (2007). Does age make a difference? Predicting physical activity of South Koreans. Psychology and Aging, 22(3), 482-493.

Saastamoinen, H. (2005). Ajankäytön trendit 1999-2000 (Trends of time use). VATT-muistioita 68. Retrieved February 22, 2007, from http://en.vatt.fi/file/vatt_publication_pdf/m68.pdf.

Sallis, J.F., Grossman, R.M., Pinski; R.B., Patterson, T.L., \& Nader, P.R. (1987). The development of scales to measure social support for diet and exercise behaviors. Preventive Medicine, 16(6), $825-836$.

Schwarzer, R., \& Fuchs, R. (1996). Self-efficacy and health behaviours. In M. Conner, \& P. Norman (Eds.), Predicting health behaviour (pp. 163-196). Buckingham: Open University Press. 
Schwarzer, R., \& Gutiérrez-Doña, B. (2005). More spousal support for men than for women: A comparison of sources and types of support. Sex Roles, 52(7), 523-532.

Schwarzer, R., \& Knoll, N. (2007). Functional roles of social support within the stress and coping process: A theoretical and empirical overview. International Journal of Psychology, 42(4), 243-252.

Schwarzer, R., \& Renner, B. (2000). Social-cognitive predictors of health behavior: Action selfefficacy and coping self-efficacy. Health Psychology, 19(5), 487-495.

Schwarzer, R., Schüz, B., Ziegelmann, J.P., Lippke, S., Luszczynska, A., \& Scholz, U. (2007). Adoption and maintenance of four health behaviors: Theory-guided longitudinal studies on dental flossing, seat belt use, dietary behavior, and physical activity. Annals of Behavioral Medicine, 33(2), 156-166.

Shaw, K., Gennat, H., O'Rourke, P., \& Del Mar, C. (2006). Exercise for overweight or obesity. Cochrane Database of Systematic Reviews 2006, 4, doi: 10.1002/14651858.CD003817.pub3.

Silverman, I.W. (2003). Gender differences in delay of gratification: A meta-analysis. Sex Roles, 49(9-10), 451-463.

Sniehotta, F.F., Scholz, U., \& Schwarzer, R. (2005a). Bridging the intention-behaviour gap: Planning, self-efficacy, and action control in the adoption and maintenance of physical exercise. Psychology \& Health, 20, 143-160.

Sniehotta, F.F., Schwarzer, R., Scholz, U., \& Schüz, B. (2005b). Action planning and coping planning for long-term lifestyle change: Theory and assessment. European Journal of Social Psychology, 35(4), 565-576.

Tangney, J.P., Baumeister, R.F., \& Boone, A.L. (2004). High self-control predicts good adjustment, less pathology, better grades, and interpersonal success. Journal of Personality, 72, 271-322.

Tuomilehto, J., Lindstrom, J., Eriksson, J.G., Valle, T.T., Hamalainen, H., Ilanne-Parikka, P., et al. (2001). Prevention of type 2 diabetes mellitus by changes in lifestyle among subjects with impaired glucose tolerance. New England Journal of Medicine, 344(18), 1343-1350.

Uutela, A., Valve, R., Talja, M., Absetz, P., Nissinen, A., \& Fogelholm, M. (2004). Health psychological theory in promoting population health in Päijät-Häme, Finland: First step towards a type 2 diabetes prevention study. Journal of Health Psychology, 9(1), 73-84.

Verhoef, M.J., Love, E.J., \& Rose, M.S. (1992). Women's social roles and their exercise participation. Women's Health; 19(4), 15-29.

Whitlock, E.P., \& Williams, S.B. (2003). The primary prevention of heart disease in women through health behavior change promotion in primary care. Women's Health Issues, 13(4), 122-141.

Wing, R.R., \& Jeffery, R.W. (1999). Benefits of recruiting participants with friends and increasing social support for weight loss and maintenance. Journal of Consulting and Clinical Psychology, $67(1), 132-138$.

\section{Appendix}

Items of the latent variables.

\section{Self-efficacy}

I can manage to carry out my exercise intentions:

(a) even if I need a long time to develop the necessary routines

(b) even if I have to try several times

(c) even if I have to change my exercise habits entirely

(d) even if I couldn't get very much support from other people in my first attempts

(e) even if I have to make a detailed plan regarding exercise

Planning

I have made a detailed plan regarding:

(a) when to exercise

(b) where to exercise 
(c) how to exercise

(d) how often to exercise

\section{Social support}

How often (in the past 3 months) have those close to you (friends, family or relatives):

(k) exercised with you

(n) encouraged you to maintain your exercise habit

(o) changed their schedule so that you could exercise together

(p) discussed exercise with you

(t) planned your leisure time together so that it included physical activity.

Table A1. Loadings of the latent variables.

\begin{tabular}{|c|c|c|c|c|}
\hline & \multicolumn{2}{|c|}{ Women } & \multicolumn{2}{|c|}{ Men } \\
\hline & Unstandardised & Standardised & Unstandardised & Standardised \\
\hline \multicolumn{5}{|c|}{ Self-efficacy $T 1$} \\
\hline $\mathrm{a}$ & 1 & 0.898 & 1 & 0.918 \\
\hline b & 0.997 & 0.907 & 0.997 & 0.932 \\
\hline $\mathrm{c}$ & 0.947 & 0.768 & 0.947 & 0.744 \\
\hline d & 0.994 & 0.825 & 0.994 & 0.800 \\
\hline $\mathrm{e}$ & 0.952 & 0.736 & 0.952 & 0.780 \\
\hline \multicolumn{5}{|c|}{ Self-efficacy $T 2$} \\
\hline $\mathbf{a}$ & 1 & 0.901 & 1 & 0.841 \\
\hline $\mathrm{b}$ & 0.997 & 0.921 & 0.997 & 0.881 \\
\hline c & 0.947 & 0.817 & 0.947 & 0.737 \\
\hline d & 0.994 & 0.798 & 0.994 & 0.771 \\
\hline e & 0.952 & 0.821 & 0.952 & 0.736 \\
\hline \multicolumn{5}{|c|}{ Planning $T 1$} \\
\hline$a$ & 1 & 0.865 & 1 & 0.872 \\
\hline b & 1.045 & 0.919 & 1.045 & 0.923 \\
\hline c & 1.076 & 0.916 & 1.076 & 0.877 \\
\hline $\mathrm{d}$ & 1.043 & 0.851 & 1.043 & 0.845 \\
\hline \multicolumn{5}{|c|}{ Planning $T 2$} \\
\hline $\mathrm{a}$ & 1 & 0.865 & 1 & 0.902 \\
\hline b & 1.045 & 0.912 & 1.045 & 0.935 \\
\hline c & 1.076 & 0.921 & 1.076 & 0.925 \\
\hline $\mathrm{d}$ & 1.043 & 0.865 & 1.043 & 0.907 \\
\hline \multicolumn{5}{|c|}{ Social support $T 1$} \\
\hline k & 1 & 0.737 & 1 & 0.705 \\
\hline $\mathrm{n}$ & 1.000 & 0.720 & 1.000 & 0.715 \\
\hline 0 & 0.747 & 0.674 & 0.747 & 0.624 \\
\hline $\mathrm{p}$ & 0.978 & 0.778 & 0.978 & 0.778 \\
\hline $\mathfrak{t}$ & 0.829 & 0.717 & 0.829 & 0.730 \\
\hline
\end{tabular}

Factorial invariance was imposed on the raw scale of the loadings. (Parameter estimates from Model 5 and Model 7.) 